\title{
Characteristics and Photocatalytics Activities of Ce-Doped ZnO Nanoparticles
}

\author{
Nadia Febiana Djaja, Rosari Saleh* \\ Departemen Fisika, Fakultas Matematika dan Ilmu Pengetahuan Alam-Universitas Indonesia, Jakarta, Indonesia. \\ Email: *rosari.saleh@ui.ac.id
}

Received November $29^{\text {th }}, 2012$; revised December $28^{\text {th }}, 2012$; accepted January $24^{\text {th }}, 2013$

\begin{abstract}
Ce-doped $\mathrm{ZnO}$ nanoparticles with various doping concentrations of cerium ion were prepared by the co-precipitation method. All prepared nanoparticles were characterized by electron spin resonance (ESR), energy-dispersive X-ray spectroscopy (EDX), X-ray diffraction (XRD) and UV-Vis diffuse reflectance spectroscopy. All nanoparticles show $\mathrm{X}$-ray diffraction pattern that matched with $\mathrm{ZnO}$ in its wurzite structure and average grain size was in the range of 13 $16 \mathrm{~nm}$. UV-Vis measurements indicated a red shift of the photophysical response of $\mathrm{ZnO}$ after doping that was exhibited in reflection spectra in the visible region between $300-800 \mathrm{~nm}$. In addition, it has been found from electron spin resonance measurements that defects, which are likely to be oxygen vacancy and an electron trapped at cerium site are formed in our Ce-doped $\mathrm{ZnO}$ particles. Photocatalytic activities of $\mathrm{Ce}$-doped $\mathrm{ZnO}$ were evaluated by irradiating the nanoparticles solution to ultraviolet light by taking methyl orange as organic dye. The experiment demonstrated that the photodegradation increased as doping concentrations increased at first and then decreased when the doping concentration exceeded 9 at $\%$. It is proposed that the photocatalytic activity is strongly dependent on the formation of oxygen vacancy and an electron trapped at cerium site.
\end{abstract}

Keywords: Cerium; Zinc Oxide; ESR; Structural Properties; Photocatalytic

\section{Introduction}

Metal oxide semiconductor materials such as $\mathrm{TiO}_{2}$ and $\mathrm{ZnO}$ have attracted extensive attention in the recent years due to their photocatalytic ability in the degradation of organic pollutant in water and air. Among various oxide semiconductor $\mathrm{TiO}_{2}$ and $\mathrm{ZnO}$ are most suitable candidate for widespread environmental applications due to their biological and chemical inertness, strong oxidation power and cost effectiveness and long-term stability against photo- and chemical corrosion [1-5]. Although $\mathrm{TiO}_{2}$ is universally considered as the most photo active catalyst, $\mathrm{ZnO}$ is a suitable alternative to $\mathrm{TiO}_{2}$ as it has similar band gap energy and its lower cost and better performance compared to $\mathrm{TiO}_{2}$ in the degradation of several organic contaminants [6]. However, the photocatalytic efficiency depends on the competition between electronhole recombination process and surface chemical reaction. It is shown that the surface chemical reactions could not occur, if recombination process of electron and hole occurs too fast.

In order to improve photocatalytic activity, some literatures have proved that the incorporation of rare earth

\footnotetext{
${ }^{*}$ Corresponding author.
}

ions doping could increase the photocurrent response and the separation of electron-hole pairs under UV illumination [7-12]. Since $\mathrm{CeO}_{2}$ has a band gap of $\sim 3 \mathrm{eV}$ and shows interesting properties that are similar to that of $\mathrm{ZnO}$, the mixed of both materials have been investigated for the searching of highly efficient photocatalysis [13]. Unfortunately, little work has been reported on the fabrication and photocatalytic activity of organic contaminants by Ce-doped $\mathrm{ZnO}$. In addition, the dopant sites, defect induced by the doping have strong impact on the structural and optical properties of Ce-doped $\mathrm{ZnO}$ [14]. So the preparation and characterization of Ce-doped $\mathrm{ZnO}$ still need further research.

Until know, different synthesis routes have been developed and reported for preparation Ce-doped $\mathrm{ZnO}$ such as pulsed laser deposition, hydrothermal method, thermal evaporation, pyrolysis wet-chemical etching, chemicalcombution process, electrochemical synthesis and sol-gel method [15-23]. In this paper, we report a systematic study on the effect of $\mathrm{Ce}$ ion as a dopant in $\mathrm{ZnO}$ nanoparticles. The samples have been prepared by co-precipitation method. The effect of Ce doping on the electronic states, structural and optical properties and the photocatalytic activity was evaluated. 


\section{Experimental}

Zinc (II) sulfate $\left(\mathrm{ZnSO}_{4} \cdot 7 \mathrm{H}_{2} \mathrm{O}, 99 \%\right)$, cerium (IV) sulfate $\left(\mathrm{Ce}\left(\mathrm{SO}_{4}\right)_{2} \cdot 4 \mathrm{H}_{2} \mathrm{O}, 99 \%\right)$ and sodium hydroxide $(\mathrm{NaOH})$ are used as zinc and cerium sources, respectively. All chemicals were used without further purification.

$\mathrm{Ce}$-doped $\mathrm{ZnO}$ nanoparticles were synthesized by reacting appropriate amounts of zinc (II) sulfate

$\left(\mathrm{ZnSO}_{4} \cdot 7 \mathrm{H}_{2} \mathrm{O}\right.$, 99\%, Merck), and cerium (IV) sulfate $\left(\mathrm{Ce}\left(\mathrm{SO}_{4}\right)_{2} \cdot 4 \mathrm{H}_{2} \mathrm{O}, 99 \%\right.$, Merck) were dissolved in distilled water. This solution then placed in an ultrasonic cleaner operating at $57 \mathrm{kHz}$ for $2 \mathrm{~h}$. After sonication the solution was stirred at room temperature. At the same time, $3.83 \mathrm{~g}$ $\mathrm{NaOH}$ was dissolved into $950 \mathrm{ml}$ de-ionized water and a homogenous solution was obtained after constant stirring. Then, the solution of alkaline was added into the solution containing $\mathrm{ZnSO}_{4} \cdot 7 \mathrm{H}_{2} \mathrm{O}$ and $\mathrm{Ce}\left(\mathrm{SO}_{4}\right)_{2} \cdot 4 \mathrm{H}_{2} \mathrm{O}$ by dropwise under constant stirring until the final $\mathrm{pH}$ of the solution reached 13. The solution was further stirred for $0.5 \mathrm{~h}$ under constant magnetic stirring and then allowed to remain at room temperature for $18 \mathrm{~h}$. The obtained precipitates were centrifuged and washed several times with ethanol and distilled water to remove residual and unwanted impurities. The final product was dried in a vacuum oven at $100^{\circ} \mathrm{C}$ for $4 \mathrm{~h}$ yielding Ce-doped $\mathrm{ZnO}$ powders.

Electron spin resonance (ESR) measurements were performed using an X-band JEOL JES-RE1X at room temperature and an X-band spectrometer equipped with a 9.1 GHz field modulation unit. The amount of sample used in all measurements was the same. DPPH was used as the standard sample served for field calibration. The crystal structures of synthesized nanoparticles were analyzed using X-ray diffractometer (XRD). The existence and composition of Ce dopants were determined by energy-dispersive X-ray spectroscopy (EDX). The UV-Vis absorption spectra of the samples was measured on a Shimadzu UV-Vis spectrophotometer with an integrating sphere and a spectral reflectance standard over a wavelength range of $250-800 \mathrm{~nm}$, by diffuse reflectance.

The photocatalytic activities of the Ce-doped $\mathrm{ZnO}$ photocatalysts were evaluated by the degradation of methyl orange (MO). The details of the measurement were described as follows: $10 \mathrm{mg}$ of Ce-doped $\mathrm{ZnO}$ as photocatalysts are dispersed under magnetic stirring for $15 \mathrm{~min}$. The light source of illumination was 20 Watt and fixed $30 \mathrm{~cm}$ above the treated solution. The decay of MO concentration during illumination process was monitored by UV-Vis absorbance measurements after aliquot sampling at regular time intervals. Control experiments without any light were also performed.

\section{Results and Discussion}

The Ce concentrations of the samples were determined using EDX measurements. Figure 1 provides representative EDX spectra for the Ce-doped $\mathrm{ZnO}$ particles. Elemental analysis revealed that the samples contain target elements within the detection limit of EDX. Quantitative characterization of the $\mathrm{Ce} / \mathrm{Zn}$ ratio was performed by calculating the area of the corresponding spectral $\mathrm{K}$ lines. The amounts of $\mathrm{Ce}$ in the $\mathrm{ZnO}$ particles was found to vary between 3 - 19 at.\%. Four different random areas in the sample were chosen and about the same Ce concentration was obtained for all of them. This result suggested that the distribution of $\mathrm{Ce}$ is homogeneously. It is seen that the amounts of $\mathrm{Ce}$ incorporated in the samples are slightly lower than their nominal composition introduced in the synthesis. The data shown in Table.1 illustrates how the $\mathrm{Ce}$ incorporation in $\mathrm{ZnO}$ particles varies as a function of the initial cations ratio used in the synthesis. It appears that the amounts of $\mathrm{Ce}$ and incorporated in the samples are slightly lower than the amounts of Ce introduced in the synthesis.

XRD patterns of Ce-doped $\mathrm{ZnO}$ samples plotted in Figure 2 showed a similar feature. All patterns were fitted by means of the MAUD program using the Rietveld to determine the crystal structure, phase and lattice parameters. All samples revealed strong XRD peaks due to the hexagonal wurtzite phase and no other impurity phases were observed. The XRD peak positions gradually change with doping, revealing interesting variations in lattice parameters $a$, and $c$ and lattice volume $V$.

The average size of the precipitate crystallites $<\mathrm{D}>$ was estimated with the Scherrer peak broadening method: $<\mathrm{D}>=0.891 / \mathrm{D} \cos \mathrm{Q}$, where 1 is the $\mathrm{X}$-ray wavelength, $\mathrm{D}$ is the line broadening at half-height and Q is the Bragg angle of the particles. From $2 \theta$ values, the inter-planar spacing $d$ of the peaks is calculated. The lattice constants,

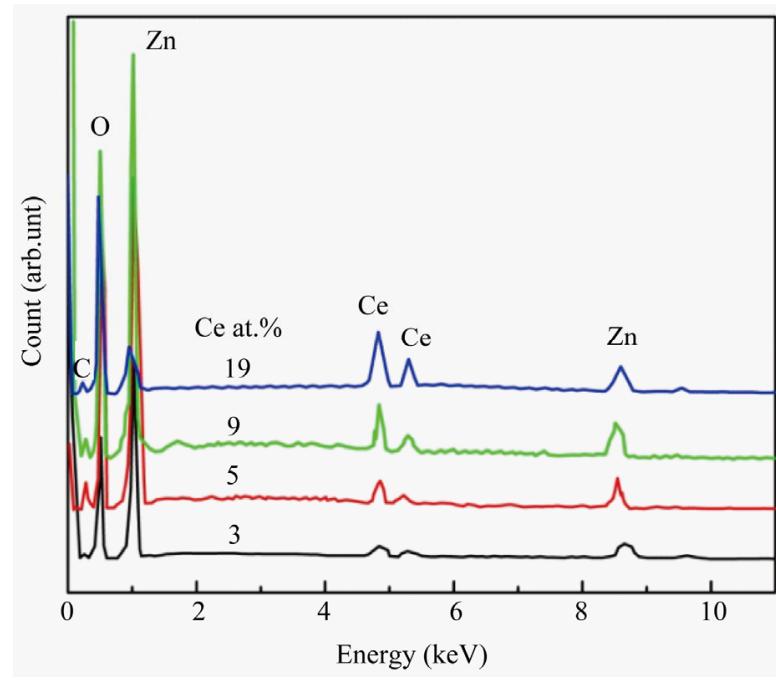

Figure 1. EDX spectra of the Ce-doped nanocrystalline ZnO particles at various doping concentrations. The spectra are shifted vertically for clarity. 


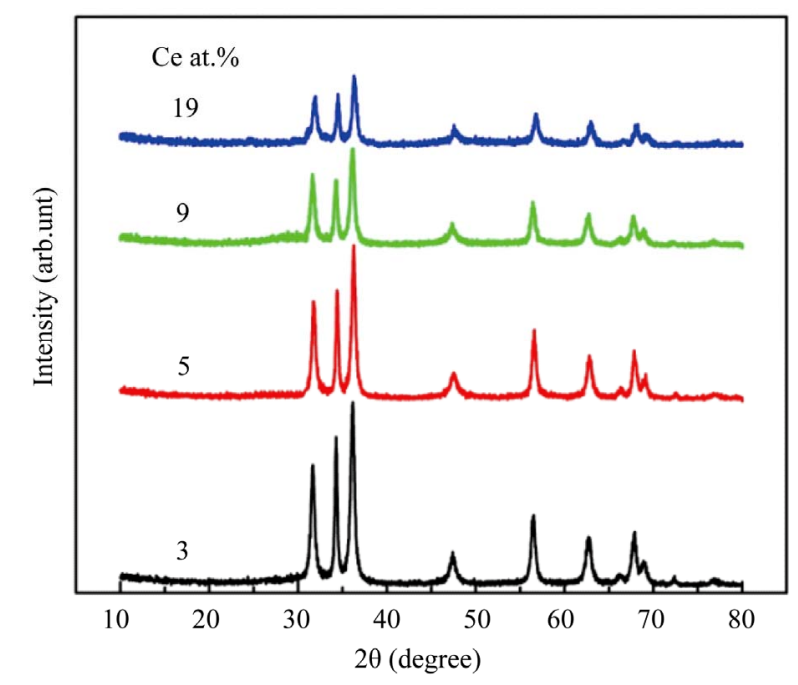

Figure 2. XRD patterns of the Ce-doped nanocrystalline ZnO particles synthesized with different concentrations of Ce.

the variation of aspect ratio $(c / a)$, lattice volume $V$, interplanar space $d$ and the average crystallite size $<\mathrm{D}>$ are also summarized in Table 1.

In fact, the ionic radii of $\mathrm{Ce}^{3+}$ and $\mathrm{Ce}^{4+}$ ions are 0.093 and $0.103 \mathrm{~nm}$, respectively, larger than $\mathrm{Zn}^{2+}$ ion, so it is difficult for $\mathrm{Ce}$ ions to enter the the $\mathrm{ZnO}$ lattice structure. However, the $c / a$ is almost constant and has good correlation with the standard value (1.60). The results suggested that the incorporation of $\mathrm{Ce}$ ion in the $\mathrm{ZnO}$ matrix has no or little effect in the entire crystal structure. George et al. [24] expected that the substitutional doping to change the bond distances reflected through the change in unit cell lattice parameters and the peak intensities can be affected by the change in electron density due to substitution of atoms. The bond-length calculated from the formula defined by Ref [24], has also tabulated in Table 1. As can be seen that the variation of bond length with respect to aspect ratio in our samples also does not follow any particular trend as reported by George et al. [24]. According to George et al. [24] the decrease in lattice parameters can be attributed to replacement of $\mathrm{Zn}$ ions with $\mathrm{Ce}$ ions while the increase in lattice paremeters can be due to interstitial incorporation of $\mathrm{Ce}$ ions in $\mathrm{ZnO}$ matrix. In addition they suggested that at low $\mathrm{Ce}$ concentrations interstitial incorporation is favored while at high Ce concentrations, substitution and interstitial incorporation of Ce are comparable. Comparing our XRD results with the results obtained from George et al. [24], we believed that the decrease in lattice parameter can be attributed to replacement of $\mathrm{Zn}$ ion with $\mathrm{Ce}$ ion in $\mathrm{ZnO}$ lattice, where both processes substitution and interstitial substitution are taken place.

Figure 3 shows the diffuse-reflectance spectra, R, as a function of wavelength for samples shown in Figure 2. The inset of Figure 3 shows the band-gap as a function of the doping concentrations obtained from diffuse reflectance spectra. The band-gap energy of the Ce-doped $\mathrm{ZnO}$ samples was calculated from the diffuse-reflectance spectra by plotting the square of the Kubelka-Munk function $\mathrm{F}(\mathrm{R})^{2}$ vs. the energy in electron volts. The linear part of the curve was extrapolated to $F(R)^{2}=0$ to calculate the direct band-gap energy. It is seen that the absorption edge shifts to lower energies/longer wavelength. It is thought that the lattice strain induced by the lattice distant could lead to some shift in the band gap. However, the deformation of lattice distance is not big enough to play a major role in the determination of the band gap. Iqbal et al. [25] in their photoluminescence measurements reported that the Ce-doped $\mathrm{ZnO}$ nanowires exhibit a large red shift of UV emission. They believed that when $\mathrm{Ce}$ ion is incorporated into $\mathrm{ZnO}$ matrix, the $\mathrm{Ce}$ electron localized states were formed and introduce electron states into the band-gap of $\mathrm{ZnO}$. These electron states locate closer to the lower edge of conduction band to form the new lowest unoccupied molecular orbital, which results in the band gap reduction and makes eventually the red shift in UV emission.

The observed ESR spectra of Ce-doped $\mathrm{ZnO}$ for various Ce compositions measured at room temperature are summarized and shown in Figure 4. All curves were normalized to each sample weight and the integrated ESR line of DPPH used as a standard. In the range of dopant investigation, the ESR spectra can satisfactorily be fitted to two Gaussian lines: 1) a narrow line with the g-value range from 2.0717 to 2.0666 and 2) a broad line with the g-value $\sim 1.98$. It is well known that Ce element has two different oxidation states, namely $\mathrm{Ce}^{3+}$ and $\mathrm{Ce}^{4+}$. Even if Cerium (IV) sulfate is used as the dopant we suspect that both $\mathrm{Ce}^{4+}$ and $\mathrm{Ce}^{3+}$ oxidation also reside in our Ce-doped $\mathrm{ZnO}$ samples. It is known that the $\mathrm{Ce}^{4+}$

Table 1. The Ce/Zn ratio introduced in the synthesis and from EDX spectra, lattice constants, lattice volume $V$, ratio of lattice parameters ( $c / a)$, bond length $l$, inter-planar space $d$ and average crystallite size of Ce-doped ZnO nanoparticle.

\begin{tabular}{ccccccccccccc}
\hline Sample & {$[\mathrm{Ce} / \mathrm{Zn}]$} & at $\%$ & $a=b(\AA)$ & $c(\AA)$ & volume $\left(\AA^{3}\right)$ & $c / a$ & $l(\AA)$ & $d_{100}$ & $d_{002}$ & $d_{101}$ & $<\mathrm{D}>\mathrm{nm}$ \\
\hline & 0.03 & 3 & 3.2567 & 5.2203 & 47.9492 & 1.6029 & 3.7443 & 2.8204 & 2.6101 & 2.4814 & 16.5 \\
\multirow{3}{*}{ Ce doped ZnO } & 0.06 & 5 & 3.2521 & 5.2166 & 47.7799 & 1.6041 & 3.7418 & 2.8164 & 2.6083 & 2.4783 & 15 \\
& 0.1 & 9 & 3.2517 & 5.2153 & 47.7563 & 1.6039 & 3.7409 & 2.8160 & 2.6076 & 2.4779 & 14 \\
& 0.2 & 19 & 3.2508 & 5.2137 & 47.7153 & 1.6038 & 3.7397 & 2.8153 & 2.6068 & 2.4772 & 13.5 \\
\hline
\end{tabular}




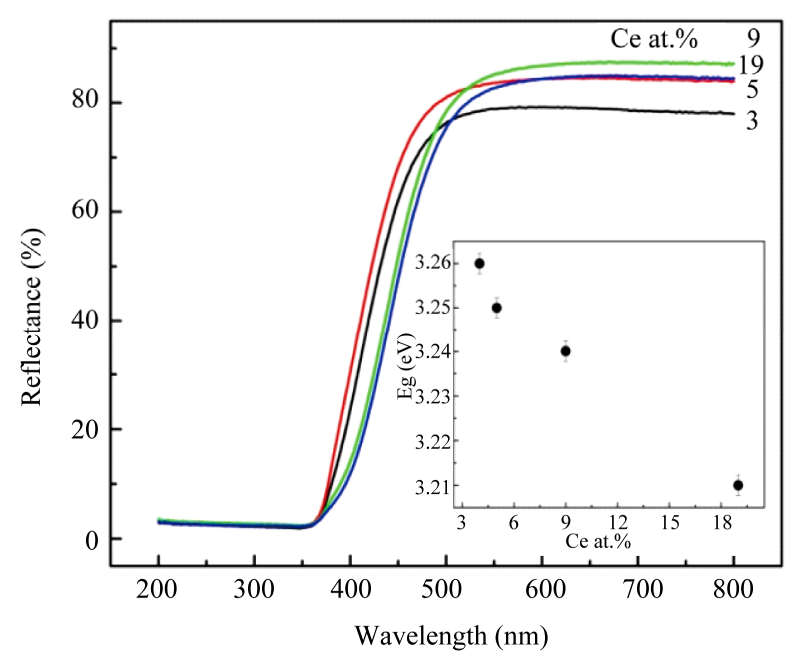

Figure 3. Diffuse-reflectance spectra of the Ce-doped nanocrystalline $\mathrm{ZnO}$ particles synthesized at various doping concentrations. The inset shows the correlated optical band gap of the Ce-doped nanocrystalline $\mathrm{ZnO}$ particles as a function of the doping concentrations.

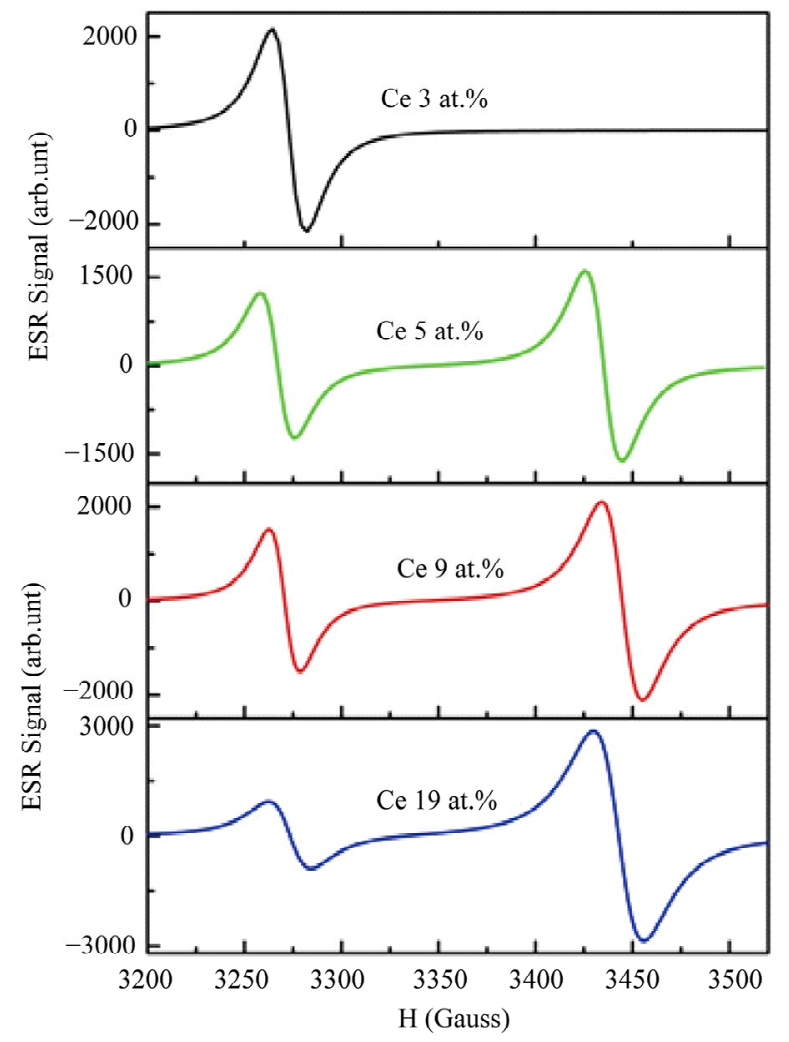

Figure 4. The ESR spectra of the Ce-doped nanocrystalline $\mathrm{ZnO}$ particles doped with various doping concentrations.

oxidation state is more stable compared to $\mathrm{Ce}^{3+}$ oxidation state in the presence of air [26]. However, $\mathrm{Ce}^{4+}$ ion is diamagnetic and cannot be detected by ESR, while the $\mathrm{Ce}^{3+}$ ion is paramagnetic with spin $1 / 2$. In addition the dopant $\mathrm{Ce}^{4+}$ ions have a strong tendency to attract elec- trons [25]. Once an electron is trapped in $\mathrm{Ce}^{4+}$ ion, a transitions between $5 \mathrm{~d}$ and $4 \mathrm{f}$ orbitals become possible [25], which could take part in an electron signal in the ESR spectrum. To compensate for the charge imbalance, the oxygen vacancy was formed $[27,28]$.

According to the first-principle theoretical studies, the oxygen vacancy has the lowest formation energy among the donor like defects but forms a deep electronic defect state [29].

It is also known that the oxygen vacancy could occur in three different charge states: 1) neutral oxygen vacancy; 2) singly ionized oxygen vacancy and 3) doubly ionized oxygen vacancy $[14,30]$. Based on g value, most of the experimental investigations of oxygen vacancies in undoped $\mathrm{ZnO}$ fall on two catagories [31] one set of reports associate oxygen vacancies with the g-value of 1.96, the other with $g$ value of 1.990. In earlier paper [32-34], it was shown that the g-value 1.96 of ESR line in undoped $\mathrm{ZnO}$ correlates well with electron conductivity and originates from shallow donors. Later, Kasai [32] and Hausmann [35] argued that shallow donors in $\mathrm{ZnO}$ are related to the oxygen vacancy, whereas the low field signal with the g-value of 1.99 is generally attributed to singly ionized oxygen vacancies or unpaired electron trapped on an oxygen vacancy site. By analyzing and comparing our ESR signal with signal reported in the literature, we believed that the ESR spectra obtained for samples in the present study can both be ascribed to $\mathrm{Ce}^{3+}$ and an unpaired electron trapped in $\mathrm{Ce}^{4+}$ (a narrow line) or $\mathrm{Ce}^{3+}$, although it is impossible to distinguish unambiguously between the two cases from knowledge of the g-value alone, since the $\mathrm{Ce}^{4+}$ ion is not paramagnetic center. A signal at $\mathrm{g}$ value of 1.98 (a broad line) has been assigned to an unpaired electron trapped on an oxygen vacancy site or singly ionized oxygen vacancy, respectively. The corresponding spin concentrations in the broad and narrow line as a function of doping concentrations have been listed in Table 2. At doping concentration of 3 at $\%$, the line shape of the sample is dominated by $\mathrm{Ce}^{3+}$ ions or an unpaired electron trapped in $\mathrm{Ce}^{4+}$. $\underline{\mathrm{In}}-$ terestingly, at this doping concentrations the signal at g-value of 1.98 was not observed. It is believed that, the concentrations of oxygen vacancy were low and made it difficult to detect the ESR signal. As the doping concentration increased, the narrow line shifted to higher applied magnetic field, and the line width increased. The line width was found in the range of approximately 18 to $21 \mathrm{G}$. Increasing the doping concentrations from 3 to 19 at $\%$, the total number of spins contributing to this line decreases, indicating a decrease in concentrations of $\mathrm{Ce}^{3+}$ ions or an unpaired electron trapped in $\mathrm{Ce}^{4+}$, while the total number of spin contributing to the broad line increased, suggesting that the concentration of oxygen vacancy increased with increasing doping concentrations. 
Table 2. The g values, peak width (Hpp) and peak area of the deconvoluted ESR signals as a function of doping concentration.

\begin{tabular}{|c|c|c|c|c|c|c|c|}
\hline \multirow{2}{*}{ Sample } & \multirow{2}{*}{$a t \%$} & \multicolumn{3}{|c|}{ Signal 1} & \multicolumn{3}{|c|}{ Signal 2} \\
\hline & & $\mathrm{g}$ value & Hpp (G) & Int. Area $\left(10^{5}\right)$ & $\mathrm{g}$ value & Hpp (G) & Int. Area $\left(10^{5}\right)$ \\
\hline \multirow{4}{*}{ Ce-doped $\mathrm{ZnO}$} & 3 & - & - & - & 2.0666 & 18.48 & 23.5 \\
\hline & 5 & 1.9761 & 18.66 & 20.6 & 2.0673 & 15.88 & 17.7 \\
\hline & 9 & 1.9788 & 21.04 & 33.9 & 2.0701 & 17.54 & 15.8 \\
\hline & 19 & 1.9765 & 25.84 & 42.5 & 2.0717 & 21.80 & 4.3 \\
\hline
\end{tabular}

The photocatalytic activity of Ce-doped $\mathrm{ZnO}$ was observed on the photodegradation of methyl orange (MO) under UV irradiation. Time dependent UV-Vis absorption spectra of the photocatalytic degradation of MO in the presence of Ce-doped samples are shown in Figure 5. It is seen that the absorbance for the maximum peak at $463 \mathrm{~nm}$ decreases, indicating the occurrence of the destruction of $\mathrm{MO}$ and the formation of some intermediates [36]. The blank test with an absence of Ce-doped $\mathrm{ZnO}$ catalyst shows little change in absorbance at $464 \mathrm{~nm}$, indicating that the catalyst and light are essential for photocatalytic degradation. Figure 6 showed the $\ln$ $\left(\mathrm{C}_{0} / \mathrm{C}_{\mathrm{t}}\right)$ as a function of time curves of the MO photodegradation using various concentration of $\mathrm{Ce}$ in $\mathrm{Ce}$-doped $\mathrm{ZnO}$ photocatalysts, where $\mathrm{C}_{0}$ and $\mathrm{C}_{\mathrm{t}}$ was the concentration of the primal and remaining $\mathrm{MO}$, respectively. It is found that all curves followed a first order reaction kinetic model, $\mathrm{Ln}\left(\mathrm{C}_{0} / \mathrm{C}_{\mathrm{t}}\right)=\mathrm{kt}$, where $\mathrm{k}$ is rate constant of the degradation.

The degradation rate of MO catalyzed by Ce-doped $\mathrm{ZnO}$ improves with increasing $\mathrm{Ce}$ doping and the $\mathrm{Ce}$ doped $\mathrm{ZnO}$ catalysts with 9 at $\%$ of Ce show the highest photodegradation rate. While the Ce-doping content exceeds 9 at $\%$, the photocatalytic activity of Ce-doped $\mathrm{ZnO}$ catalysts decreases with an increase of the Ce-doping content.

To explain the cause of Ce-doped $\mathrm{ZnO}$ catalysts in photocatalytic activity, it is important to understand the photocatalytic mechanism in semiconductor. It is known that upon irradiation by light with energy higher or equal to the band gap, valence band electron can be excited to the conduction band leaving a hole behind. If the charge separation is maintained and the catalysts are dispersed in the MO, the electron and hole could migrate to the particle surface and participated in redox reaction with the adsorbed organic species [37,38]. On the basis of our photocatalytic results, it is believed that the difference in photocatalytic activity with doping concentrations not really relates to the surface adsorption ability, but also relates to the influence of doping concentration on structure and the concentration of electron acceptor $\left(\mathrm{Ce}^{4+}\right.$ ions) and oxygen vacancies [36]. Li et al. [39] based on photoluminescence measurements proved that Ce doping can

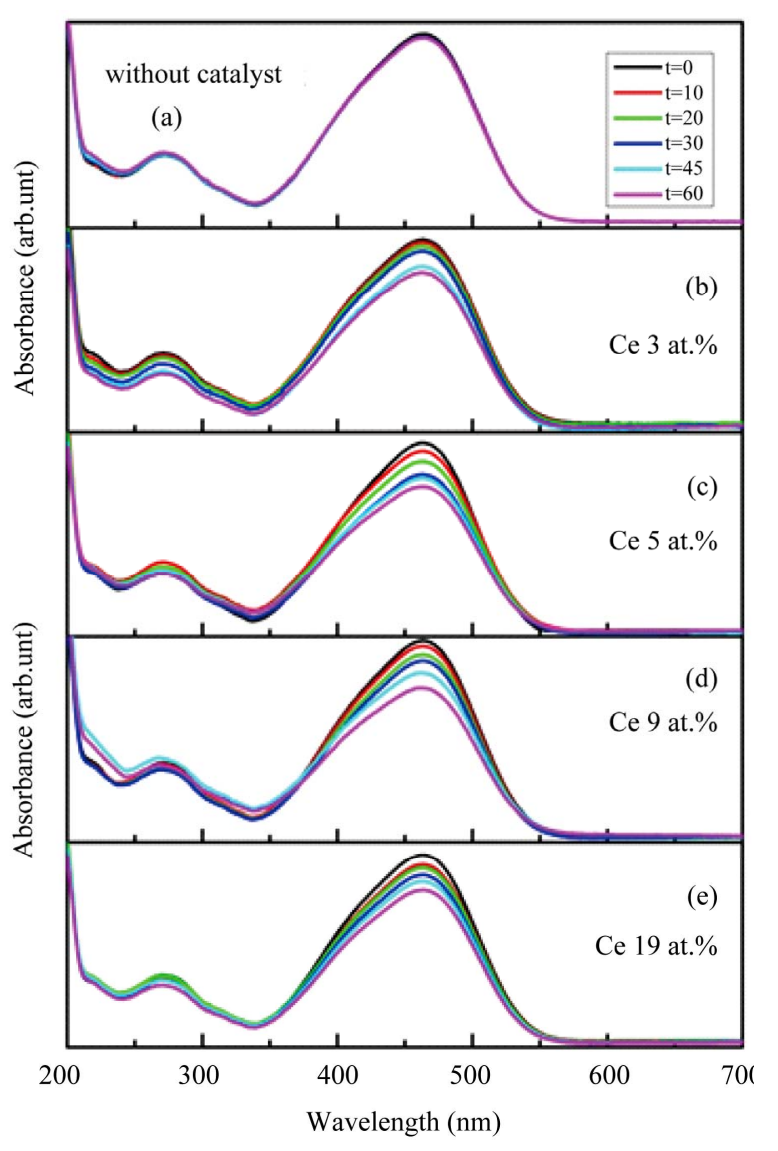

Figure 5. Time dependent UV-Vis absorption spectra of the photocatalytic degradation of methyl-orange in the presence of Ce-doped $\mathrm{ZnO}$ samples.

accelerate the separation efficiency of charge carriers. According to their results the $\mathrm{Ce} 4 \mathrm{f}$ level plays an important role in interfacial charge transfer and elimination of electron-hole recombinations. Moreover, Ce ions could act as an effective electron scavenger to trap the conduction band electrons and efficiently transfer the photogenerated electrons. In addition to the reaction process describe above, the defect states such as oxygen vacancy could also serve as favorable electron scavenger to trap electron, recombination is prevented and subsequent redox reactions can occur $[36,40]$.

In our investigation, it is apparent from the ESR spec- 


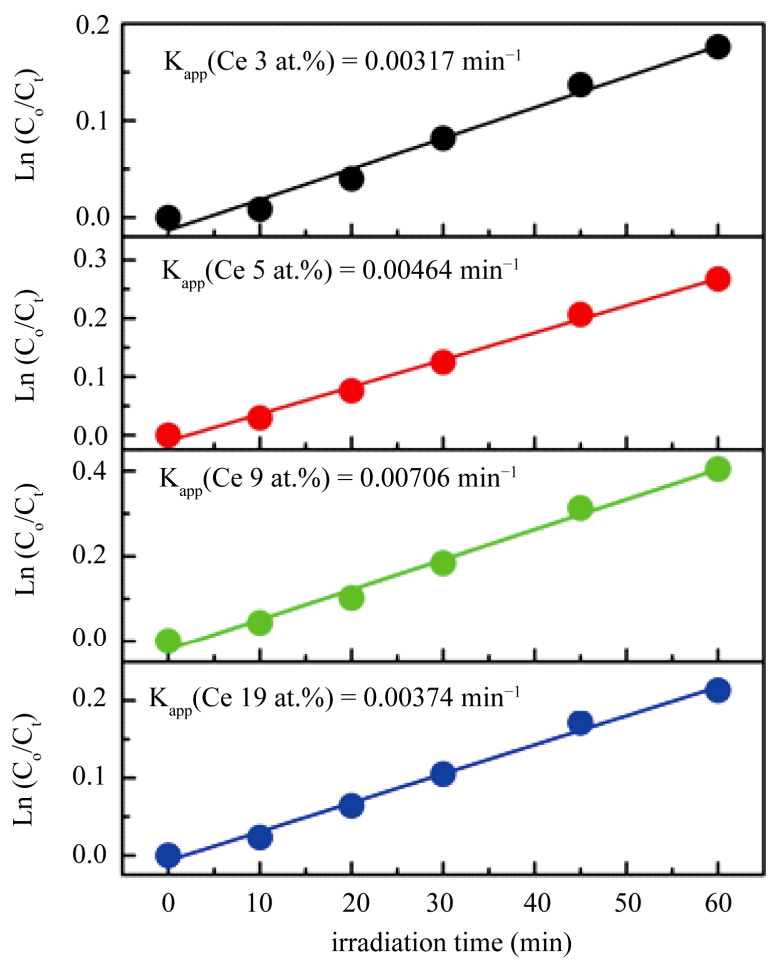

Figure 6. The $\operatorname{Ln}\left(C_{0} / C_{t}\right)$ as a function of time curves of the methyl-orange photodegradation using various concentration of $\mathrm{Ce}$ in Ce-doped $\mathrm{ZnO}$ photocatalyst.

tra of Ce-doped $\mathrm{ZnO}$ catalysts that there is an increase and a decrease in oxygen vacancy and Ce ion signals, respectively. It is therefore quite certain that there exist two competing trapping centers for photogenerated electrons. It is suggested that the formation of trapping center energy levels might be the reason to eliminate or reduce the probability of electron-hole recombination and to enhance the photocatalytic activity. According to the ESR results, the total spin concentrations in both trapping centers of 9 at $\%$ was the largest as can be seen in Figure 7 , consequently the probability of the photogenerated electron trapped in these center was the highest and the separation of electron and hole pairs is the most efficient. That might be the reason why the optimal dosage of ceria was 9 at $\%$ under UV illumination. Our results are consistent with the results of earlier studies of photoluminescence and photocatalytic in Ce-doped $\mathrm{TiO}_{2}$ samples $[39,41,42]$, which suggested that the lower photoluminescence might indicate fewer electron-hole recombination and lead to the increase in photocatalytic activity.

\section{Conclusions}

A serie of Ce-doped $\mathrm{ZnO}$ particles have been prepared by a co-precipitation method and their structural, optical and photocatalytic activation as a function of doping concentration is investigated. From these studies the major findings are the following.

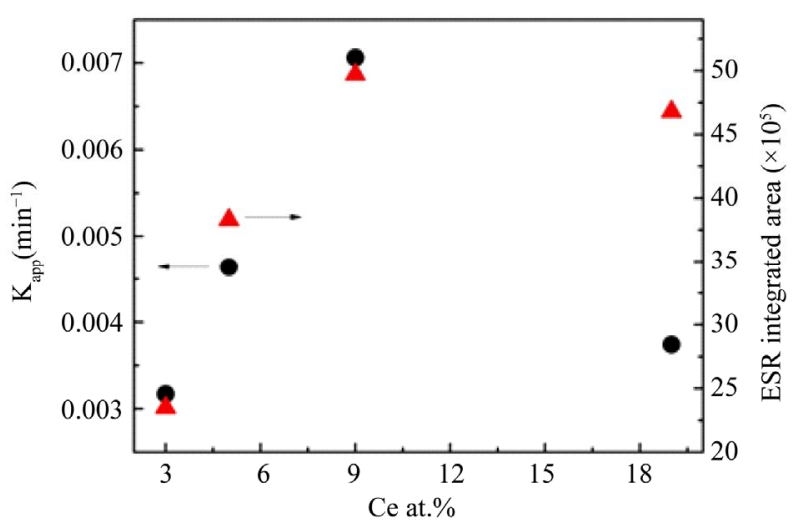

Figure 7. Correlation between rate constant with the total spin concentrations in both trapping centers as a function Ce doping concentration in Ce-doped $\mathrm{ZnO}$ samples.

1) The characteristic of these samples exhibited that Ce dopant has a strong effect on structural and optical properties, which could be shown in a significant reduction in the band gap, the formation of new states due to doping level and the presence of an oxygen vacancy.

2) From the ESR spectra in our dopant range, we obtained two resonances: (1) a narrow line with g-value range from 2.0717 to 2.0666 attributed to an electron trapped in $\mathrm{Ce}^{4+}$ and (2) a broad line with a g-value remainning unchanged at 1.98 assigned to the presence of oxygen vacancy. With increasing doping concentrations, the number of spins due to oxygen vacancy increased, while the number of spins due to an electron trapped in $\mathrm{Ce}^{4+}$ ions decreased.

3) It just appears that the observed change in the number of total spin in both paramagnetic centers is accompanied by a change of photocatalytic activity.

4) Our results has suggested that the photocatalytic activity mechanisms are therefore strongly determined by two different electron trapping mechanisms, and therefore two different trapping paths involving both paramagnetic centers that significantly enhance and better separate electron-hole pairs.

5) Moreover, it is also shown that the photocatalytic activity increased with the increase of cerium ion content and then decreased when the cerium ion exceeded its optimal value.

\section{REFERENCES}

[1] O. Carp, C. L. Huisman and A. Reller, "Photoinduced Reactivity of Titanium Dioxide," Progress in Solid State Chemistry, Vol. 32, No. 1-2, 2004, pp. 33-177. doi:10.1016/j.progsolidstchem.2004.08.001

[2] I. K. Konstantinou and T. A. Albanis, "TiO ${ }_{2}$-Assisted Photocatalytic Degradation of Azo Dyes in Aqueous Solution: Kinetic and Mechanistic Investigations: A Review," Applied Catalysis B: Environmental, Vol. 49, No. 1, 2004, pp. 1-14. doi:10.1016/j.apcatb.2003.11.010 
[3] S. Tanemura, L. Miao, W. Wunderlich, M. Tanemura, Y. Mori, S. Toh and K. Kaneko, "Fabrication and Characterization of Anatase/Rutile- $\mathrm{TiO}_{2}$ Thin Films by Magnetron Sputtering: A Review," Science and Technology of Advanced Materials, Vol. 6, No. 1, 2005, p. 11. doi:10.1016/j.stam.2004.06.002

[4] G. K. Mor, O. K. Varghese, M. Paulose, K. Shankar and C. A. Grimes, "A Review on Highly Ordered, Vertically Oriented $\mathrm{TiO}_{2}$ Nanotube Arrays: Fabrication, Material Properties, and Solar Energy Applications," Solar Energy Materials and Solar Cells, Vol. 90, No. 14, 2006, pp. 2011-2075. doi:10.1016/j.solmat.2006.04.007

[5] M. Ni, M. K. H. Leung, D. Y. C. Leung and K. Sumathy, "A Review and Recent Developments in Photocatalytic Water-Splitting Using $\mathrm{TiO}_{2}$ for Hydrogen Production," Renewable and Sustainable Energy Reviews, Vol. 11, No. 3, 2007, pp. 401-425. doi:10.1016/j.rser.2005.01.009

[6] S. Anandan, A. Vinu, T. Mori, N. Gokulakrishnan, P. Srinivasu, V. Murugesan and K. Ariga, "Photocatalytic Degradation of 2,4,6-Trichlorophenol Using Lanthanum Doped ZnO in Aqueous Suspension," Catalysis Communications, Vol. 8, No. 9, 2007, pp. 1377-1382. doi:10.1016/j.catcom.2006.12.001

[7] T.-X. Liu, X.-Z. Li and F.-B. Li, "Enhanced PhotocataLytic Activity of $\mathrm{Ce}^{3+}-\mathrm{TiO}_{2}$ Hydrosols in Aqueous and Gaseous Phases," Chemical Engineering Journal, Vol. 157, No. 2-3, 2010, pp. 475-482. doi:10.1016/j.cej.2009.12.010

[8] Y. Q. Wang, H. M. Cheng, Y. Z. Hao, J. M. Ma, W. H. Li and S. M. Cai, "Photoelectrochemical Properties of MetalIon-Doped $\mathrm{TiO}_{2}$ Nanocrystalline Electrodes," Thin Solid Films, Vol. 349, No. 1-2, 1999, pp. 120-125. doi:10.1016/S0040-6090(99)00239-4

[9] A.-W. Xu, Y. Gao and H.-Q. Liu, "The Preparation, Characterization, and Their Photocatalytic Activities of Rare-Earth-Doped $\mathrm{TiO}_{2}$ Nanoparticles," Journal of Catalysis, Vol. 207, No. 2, 2002, pp. 151-157. doi:10.1006/jcat.2002.3539

[10] W. Y. Su, E. X. Chen, L. Wu, X. C. Wang, X. X. Wang and X. Z. Fu, "Visible Light Photocatalysis on Praseodymium(III)-Nitrate-Modified $\mathrm{TiO}_{2}$ Prepared by an Ultrasound Method," Applied Catalysis B: Environmental, Vol. 77, No. 3-4, 2008, pp. 264-271. doi:10.1016/j.apcatb.2007.04.015

[11] Z. M. Shi and L. N. Jin, "Influence of $\mathrm{La}^{3+} / \mathrm{Ce}^{3+}$-Doping on Phase Transformation and Crystal Growth in $\mathrm{TiO}_{2}-15$ wt\% ZnO Gels," Journal of Non-Crystalline Solids, Vol. 35, No. 3, 2009, pp. 213-220. doi:10.1016/j.jnoncrysol.2008.10.010

[12] C. H. Liang, C. S. Liu, F. B. Li and F. Wu, "The Effect of Praseodymium on the Adsorption and Photocatalytic Degradation of Azo Dye in Aqueous $\mathrm{Pr}^{3+}-\mathrm{TiO}_{2}$ Suspension," Chemical Engineering Journal, Vol. 147, No. 2-3, 2009, pp. 219-225. doi:10.1016/j.cej.2008.07.004

[13] G.-R. Li, X.-H. Lu, W.-X. Zhao, C.-Y. Su and Y.-X. Tong, "Controllable Electrochemical Synthesis of $\mathrm{Ce}^{4+}$ Doped ZnO Nanostructures from Nanotubes to Nanorods and Nanocages," Crystal Growth and Design, Vol. 8, No. 4, 2008, pp. 1276-1281. doi:10.1021/cg7009995
[14] J. H. Yang, M. Gao, L. L. Yang, Y. J. Zhang, J. H. Lang, D. D. Wang, Y. X. Wang, H. L. Liu and H. G. Fan, "Low-Temperature Growth and Optical Properties of Ce-Doped ZnO Nanorods," Applied Surface Science, Vol. 255, No. 5, 2008, pp. 2646-2650. doi:10.1016/j.apsusc.2008.08.001

[15] J.-R. Duclère, B. Doggett, M. O. Henry, E. McGlynn, R. T. Rajendra Kumar, J.-P. Mosnier, A. Perrin and M. Guilloux-Viry, "(20-23) ZnO Thin Films Grown by Pulsed Laser Deposition on $\mathrm{CeO}_{2}$-Buffered r-Sapphire Substrate," Journal of Applied Physics, Vol. 101, 2007, p. 13509. doi: $10.1063 / 1.2404782$

[16] R. Pérez-Casero, A. Gutiérrez-Llorente, O. Pons-Y-Moll, W. Seiler, R. M. Defourneau, D. Defourneau, E. Millon, J. Perrière, P. Goldner and B. Viana, "Er-Doped ZnO Thin Films Grown by Pulsed-Laser Deposition," Journal of Applied Physics, Vol. 97, 2005, p. 54905. doi:10.1063/1.1858058

[17] X. M. Teng, H. T. Fan, S. S. Pan, C. Ye and G. H. Li, "Influence of Annealing on the Structural and Optical Properties of ZnO:Tb Thin Films," Journal of Applied Physics, Vol. 100, 2006, p. 53507. doi:10.1063/1.2227268

[18] J. S. John, J. L. Coffer, Y. Chen and R. F. Pinizzotto, "Size Control of Erbium-Doped Silicon Nanocrystals," Applied Physics Letter, Vol. 77, 2000, p. 1635. doi:10.1063/1.1309022

[19] J. L. Bubendorff, J. Ebothe, A. El Hichou, R. Dounia and M. Addou, "Luminescent Spectroscopy and Imaging of Textured Sprayed Er-Doped ZnO Films in the Near Ultraviolet and Visible Regions," Journal of Applied Physics, Vol. 100, 2006, p. 14505. doi:10.1063/1.2211347

[20] M. Alaoui Lamrani, M. Addou, Z. Soofiani, B. Sahraoui, J. Ebothé, A. El Hichou, N. Fellahi, J. C. Bernède and R. Dounia, "Cathodoluminescent and Nonlinear Optical Properties of Undoped and Erbium Doped Nanostructured ZnO Films Deposited by Spray Pyrolysis," Optics Communications, Vol. 277, No. 1, 2007, pp. 196-201. doi:10.1016/j.optcom.2007.04.033

[21] Z. Sofiani, S. Bouchta and M. Addou, "Third Harmonic Generation in Undoped and X Doped ZnO Films (X: Ce, F, Er, Al, Sn) Deposited by Spray Pyrolysis," Journal of Applied Physics, Vol. 101, 2007, p. 63104. doi:10.1063/1.2711143

[22] N. Mais, J. P. Reithmaier, A. Forchel, M. Kohls, L. Spanhel and G. Müller, "Er Doped Nanocrystalline ZnO Planar Waveguide Structures for $1.55 \mu \mathrm{m}$ Amplifier Applications," Applied Physics Letter, Vol. 75, 2005, p. 1999. doi:10.1063/1.124897

[23] Y. Liu, Q. Yang and C. Xu, "Single-Narrow-Band Red Upconversion Fluorescence of ZnO Nanocrystals Codoped with $\mathrm{Er}$ and $\mathrm{Yb}$ and Its Achieving Mechanism," Journal of Applied Physics, Vol. 104, 2008, p. 64701. doi:10.1063/1.2980326

[24] A. George, S. K. Sharma, S. Chawla, M. M. Malik and M. S. Qureshi, "Detailed of X-Ray Diffraction and Photoluminescence Studies of Ce Doped ZnO Nanocrystals," Journal of Alloys and Compounds, Vol. 509, No. 20, 2011, pp. 5942-5946. doi:10.1016/j.jallcom.2011.03.017 
[25] J. Iqbal, X. F. Liu, H. C. Zhu, C. C. Pan, Y. Zhang, D. P. $\mathrm{Yu}$ and R. H. Yu, "Trapping of Ce Electrons in Band Gap and Room Temperature Ferromagnetism of $\mathrm{Ce}^{4+}$ Doped ZnO Nanowires," Journal of Applied Physics, Vol. 106, 2009, p. 83515. doi:10.1063/1.3245325

[26] J. H. Lang, Q. Han, J. H. Yang, C. S. Li, X. Li, L. L. Yang, Y. J. Zhang, M. Gao, D. D. Wang and J. Cao, "Fabrication and Optical Properties of Ce-Doped $\mathrm{ZnO}$ Nanorods," Journal of Applied Physics, Vol. 107, 2010, p. 74302. doi:10.1063/1.3318613

[27] L. R. Shah, W. G. Wang, H. Zhu, B. Ali, Y. Q. Song, H. W. Zhang, S. I. Shah and J. Q. Xiao, "Role of Dopant, Defect, and Host Oxide in the Observed Room Temperature Ferromagnetism: $\mathrm{Co}-\mathrm{ZnO}$ versus $\mathrm{Co}-\mathrm{CeO}_{2}$," Journal of Applied Physics, Vol. 105, 2009, p. 7C515. doi:10.1063/1.3068648

[28] A. Thurber, K. M. Reddy, V. Shutthanandan, M. H. Engelhard, C. Wang, J. Hays and A. Punnoose, "Ferromagnetism in Chemically Synthesized $\mathrm{CeO}_{2}$ Nanoparticles by Ni Doping," Physics Reviews B, Vol. 76, No. 16, 2007, p. 165206. doi:10.1103/PhysRevB.76.165206

[29] M. A. Mahmood, S. Baruah and J. Dutta, "Enhanced Visible Light Photocatalysis by Manganese Doping or Rapid Crystallization with ZnO Nanoparticles," Materials Chemistry and Physics, Vol. 130, No. 1-2, 2011, pp. 531535. doi:10.1016/j.matchemphys.2011.07.018

[30] W. Li, D. Mao, F. Zhang, X. Wang, X. Liu, S. Zou, Y. Zhu, Q. Li and J. Xu, "Characteristics of ZnO:Zn Phosphor Thin Films by Post-Deposition Annealing," Nuclear Instruments and Methods in Physics Research Section B: Beam Interactions with Materials and Atoms, Vol. 169, No. 1-4, 2000, pp. 59-63. doi:10.1016/S0168-583X(00)00017-3

[31] A. Jagannatha Reddy, M. K. Kokila, H. Nagabhushana, R. P. S. Chakradhar, C. Shivakumara, J. L. Rao and B. M. Nagabhushana, "Structural, optical and EPR studies on $\mathrm{ZnO}: \mathrm{Cu}$ Nanopowders Prepared via Low Temperature Solution Combustion Synthesis," Journal of Alloys and Compounds, Vol. 509, No. 17, 2011, pp. 5349-5355. doi:10.1016/i.jallcom.2011.02.043

[32] P. H. Kasai, "Electron Spin Resonance Studies of Donors and Acceptors in ZnO," Physics Reviews, Vol. 130, No. 3, 1963, pp. 989-995. doi:10.1103/PhysRev.130.989

[33] K. M. Sancier, "ESR Investigation of Photodamage to Zinc Oxide Powders," Surface Science, Vol. 21, No. 1, 1970, pp. 1-11. doi:10.1016/0039-6028(70)90059-2
[34] M. Schulz, "ESR Experiments on Ga Donors in $\mathrm{ZnO}$ Crystals," Physica Status Solidi (A), Vol. 27, No. 1, 1975, pp. K5-K8. doi:10.1002/pssa.2210270140

[35] A. Hausmann and B. Schallenberger, "Interstitial Oxygen in Zinc Oxide Single Crystals," Zeitschrift fur Physik, Vol. 31, 1978, pp. 269-273.

[36] Y. H. Zheng, C. Q. Chen, Y. Y. Zhan, X. Y. Lin, Q. Zheng, K. M. Wei, J. F. Zhu and Y. J. Zhu, "Luminescence and Photocatalytic Activity of ZnO Nanocrystals: Correlation between Structure and Property," Inorganic Chemistry, Vol. 46, No. 16, 2007, pp. 6675-6682. doi:10.1021/ic062394m

[37] J. Gupta, K. C. Barick and D. Bahadur, "Defect Mediated Photocatalytic Activity in Shape-Controlled ZnO Nanostructures," Journal Alloys and Compounds, Vol. 509, No. 23, 2011, pp. 6725-6730. doi:10.1016/j.jallcom.2011.03.157

[38] N. Daneshvar, D. Salari and A. R. Khataee, "Photocatalytic Degradation of Azo Dye Acid Red 14 in Water on $\mathrm{ZnO}$ as an Alternative Catalyst to $\mathrm{TiO}_{2}$," Journal of Photochemistry and Photobiology A: Chemistry, Vol. 162, No. 2-3, 2004, pp. 317-322. doi:10.1016/S1010-6030(03)00378-2

[39] F. B. Li, X. Z. Li, M. F. Hou, K. W. Cheah and W. C. H. Choy, "Enhanced Photocatalytic Activity of $\mathrm{Ce}^{3+}-\mathrm{TiO}_{2}$ for 2-Mercaptobenzothiazole Degradation in Aqueous Suspension for Odour Control," Applied Catalysis A: General, Vol. 285, No. 1-2, 2005, pp. 181-189. doi:10.1016/j.apcata.2005.02.025

[40] C. L. Wu, Li Shen, H. G. Yu, Q. L. Huang and Y. C. Zhang, "Synthesis of Sn-Doped ZnO Nanorods and Their Photocatalytic Properties," Materials Research Bulletin, Vol. 46, No. 7, 2011, pp. 1107-1112. doi:10.1016/j.materresbull.2011.02.043

[41] W. L. Xue, G. W. Zhang, X. F. Xu, X. L. Yang, C. J. Liu and Y. H. Xu, "Preparation of Titania Nanotubes Doped with Cerium and Their Photocatalytic Activity for Glyphosate," Chemical Engineering Journal, Vol. 167, No. 1, 2011, pp. 397-402. doi:10.1016/j.cej.2011.01.007

[42] T.-X. Liua, X.-Z. Li and F.-B. Li, "Enhanced Photocatalytic Activity of $\mathrm{Ce}^{3+}-\mathrm{TiO}_{2}$ Hydrosols in Aqueous and Gaseous Phases," Chemical Engineering Journal, Vol. 157, No. 2-3, 2010, pp. 475-482. doi:10.1016/j.cej.2009.12.010 